\title{
THE INFLUENCE OF SEASONALITY AND WEATHER CHANGES ON PREMATURE BIRTH INCIDENCE
}

\author{
DANIEL MURESAN ${ }^{1 *}$, ADELINA STAICU ${ }^{1 *}$, GABRIELA ZAHARIE ${ }^{2}$, \\ CLAUDIU MARGINEAN ${ }^{3}$, IOANA CRISTINA ROTAR ${ }^{1}$
}

\author{
${ }^{1} 1^{\text {st }}$ Obstetrics and Gynecology Department, Iuliu Hatieganu University of \\ Medicine and Pharmacy Cluj-Napoca, Romania \\ ${ }^{2}$ Neonatology Department, Iuliu Hatieganu University of Medicine and Pharmacy \\ Cluj-Napoca, Romania \\ ${ }^{3}$ Department of Obstetrics and Gynecology I, University of Medicine and \\ Pharmacy of Targu Mures, Romania \\ * all authors have equal contributions to this study
}

\section{Abstract}

Background: Although the effects of meteorological factors on the general population health are widely documented, little is known about their influence on human pregnancy and birth. The present study aims at analyzing the influence of the atmospheric conditions on premature births.

Method: One hundred and eight nine cases of premature births were included in the study, with a gestational age between 24 to 37 weeks of amenorrhea. Cases with antepartum fetal death and those with uncertain gestational age have been excluded. Daily weather data were obtained using http://www.wunderground.com site.

A Pearson's product-moment correlation was run to assess the relationship between weekly preterm birth incidence and the total number of premature births and the mean maximum and minimum temperature (Tmax, Tmin), maximum and minimum average humidity (Umax, Umin), maximum and minimum atmospheric pressure mean (P max, $P$ min), average wind speed and average quantity precipitations, calculated for one calendar week.

Results: Approximately $7.7 \%$ of all births during the study period occurred before 37 weeks of gestation, the main reason for hospitalization being premature rupture of membranes (45\%). The analysis revealed a moderate positive correlation between weekly preterm birth incidence and the average temperature $(r=0.306, n=52$, $p=0.027)$ and a moderate positive correlation between weekly preterm birth incidence and temperature variation ( $r=0.307, n=52, p=0.007)$. Our study found no significant statistic correlation between the humidity variation, pressure variation, and wind speed.

Conclusions: The incidence of premature births can be influenced by variations of specific weather factors, especially during the weeks characterized by large fluctuations in temperature. The results obtained might inspire the construction of multicenter studies to investigate more thoroughly the adverse effects of some meteorological factors that can influence the outcomes of human pregnancy.

Keywords: preterm delivery, meteorological parameters, exposure, climate changes, seasonality

Manuscript received: 23.10 .2016

Accepted: 28.11 .2016

Address for correspondence: muresandaniel01@yahoo.com 


\section{Introduction}

Preterm birth (PB) is defined as one that occurs between 20 and 37 weeks of gestation [1]. It represents the leading cause of neonatal mortality and also a major global public health issue [2].

Although we can identify the majority of risk factors, the pathophysiological pathways of preterm birth still remains unresolved, this fact being supported by the growing number of $\mathrm{PB}$ registered in recent years [3].

Furthermore, surviving infants present an increased long term risk of impaired neurodevelopment, metabolic syndrome or hypertension, representing an important current issue of care cost, family and society burdens [4].

In the last decades, an increased interest has beenis observed concerning the influence of environmental factors on the general population health [5].

Due to their limited ability to maintain temperature balance [6], pregnant women could be affected by weather and environmental factors, therefore the meteorological changes may influence the birth outcomes [7].

Recent studies associate the short-term exposure to extremely high [7] or low temperature with an increased risk of preterm birth [6]. Seasonal patterns of preterm birth have been shown to differ from country to country.

Higher incidence of preterm birth was noticed during the winter in the northern latitudes countries such as England [8] or Sweden [6], while during spring and summer, the peak was registered in the countries towards southern latitudes such as Greece or Japan $[9,10]$, thus suggesting a possible involvement in the PB etiology of factors that are different between geographic locations, such as the temperature [7].

The objective of the present study was to analyze on a weekly basis, the possible correlation between the incidence of preterm birth and several meteorological parameters, in an attempt to identify if the weather has a relevant impact on preterm birth in the region of Transylvania, Romania.

To our knowledge, this is the first study to explore the effects of atmospheric conditions on the incidence of premature births in the temperate climate of Romania.

\section{Material and methods Study population}

A retrospective study was performed. All preterm birth (PB) recorded in the 1st Obstetrics and Gynecology Clinic of Cluj-Napoca, Romania ( $\mathrm{n}=138$ cases) between 1.01.2014 and 31.12.2014 were included in the study. All the patients were residents of Cluj-Napoca, a city from the northwest region of Romania.

Preterm delivery was considered as a birth before 37 completed weeks of gestation, having the gestational age confirmed by early ultrasound examination during the first trimester of pregnancy. Patients with an uncertain gestational age (lack of first trimester ultrasound) or antepartum fetal death were excluded. The study protocol was approved by the local ethics committee.

\section{Environmental data}

The Transylvanian Plateau is an area of 26,675 square $\mathrm{km}$, representing about $11.25 \%$ of Romanian territory. As it is surrounded by the Carpathian mountain chain the region presents a temperate climate, with oceanic influences, due to a large opening in the North-Western part, which ensures the circulation of air masses from the Western and North-Western part of the continent $[11,12]$.

The expansion of the surrounding mountains leads to differences in altitude of some hundred meters, which leads to Foehn effects in the neighboring plateaus and hills and manifest as a sudden rise in temperature at the beginning of spring, rapid snow melt and intense winds [13].

As a rule, the relief with altitudes between 350 and $550-800 \mathrm{~m}$ ensures a relative uniformity regarding the expansion of the values of climate elements. The mean temperature per year ranges from $8^{\circ}$ to $11^{\circ}$, lower in the Eastern part. The mean temperature in summer is between $18^{\circ}$ and $21^{\circ}$, whereas the mean temperature in winter lies between $-3^{\circ}$ and $-5^{\circ}$. Yearly the region has between $500-$ $700 \mathrm{~mm}$ rainfall, mainly during May - June, the least during the cold season. The relative humidity is $70-75 \%$, higher $(>80 \%)$ during the winter months, and lower during summer, $65-70 \%$ [14,15].

\section{Statistical analysis}

Daily weather data for the year 2014 were obtained using http://www.wunderground.com [16]. For every week the following parameters were recorded: average weekly temperature and its variation, average weekly humidity and its weekly variation, average weekly atmospheric pressure and its weekly variation, average weekly wind speed and average weekly precipitation quantity. The weekly variation of a parameter is defined as the difference between the minimal and maximal values during a certain week.

The statistical analysis was performed with the SPSS software package 17.0®. For correlation analysis Pearson correlation and bivariate regression were used. The number of $\mathrm{PB}$ was considered as the dependent variables and the meteorological factors were the independent variables. A value was considered significant in case of $p<0.05$.

\section{Results}

A total number of 1803 births were recorded in 2014 in $1^{\text {st }}$ Clinic of Obstetrics and Gynecology Cluj-Napoca; $138(7.65 \%)$ having occurred before 37 weeks of gestation (WG) resulting in 161 premature infants and totalizing 2493 days of hospitalization.

The characteristics of the study population are presented in Table I.

The median gestation age at admission was 33 weeks, ranging between 24 and 36 weeks. The average birth weight was $2103 \mathrm{~g}$, with a minimal value of $490 \mathrm{~g}$ and a maximal value of $3400 \mathrm{~g}$. Premature rupture of membranes (PROM) was reported in 70 cases $(50.35 \%)$ being a major 
risk factor for prematurity in our hospital.

The monthly incidence of PB in 2014 and the monthly meteorological parameters are described in Table II. In the present study the frequency of premature delivery was significantly higher in May, June and July, $46 \%$ of all PB cases being reported in these months. The highest absolute value was recorded in July (17.99\%). The maximum number of preterm births recorded in a week was represented by 10 PB noted in the third week of July. From the total number of weeks, in 7 weeks (not consecutively) no preterm birth was reported.

Our study did not show any statistically significant correlation between the $\mathrm{PB}$ and humidity variation, pressure variation, wind speed or precipitation as demonstrated in Table III.

When analyzing the temperature characteristics of 2014 a mean maximum temperature of $16^{\circ} \mathrm{C}$ and mean minimum temperature of $6^{\circ} \mathrm{C}$ were recorded, not different from the usual mean temperature per year of the region. The maximum temperature value of $35^{\circ} \mathrm{C}$ was observed in August and the minimum temperature value of $-18^{\circ} \mathrm{C}$ in December.

The preterm births more frequently occurred during weeks with the biggest temperature differences.

A Pearson's product-moment correlation was run to assess the relationship between weekly preterm birth

Table I. Clinical characteristics of the study population.

\begin{tabular}{|c|c|}
\hline Maternal age (\%) & $\begin{array}{l}<20 \text { years }-4.35 \\
20-34 \text { years }-70.29 \\
>34 \text { years }-25.36\end{array}$ \\
\hline $\begin{array}{l}\text { Preterm birth subgroups by WG } \\
\text { (\%) }\end{array}$ & $\begin{array}{l}24-27 W G-7.25 \\
28-30 W G-14.49 \\
31-33 W G-23.91 \\
34-36 \text { WG - } 54.35\end{array}$ \\
\hline Birth weight (g) & $\begin{array}{l}\text { average }-2103 \\
\min -490 \\
\max -3400\end{array}$ \\
\hline Parity (\%) & $\begin{array}{l}\text { IP }-67.39 \\
>\text { IP }-32.61\end{array}$ \\
\hline Prenatal care (\%) & $\begin{array}{l}\text { inadequate/absent }-88.41 \\
\text { adequate }-11.59\end{array}$ \\
\hline
\end{tabular}

incidence and the meteorological parameters defined in the Method section Table III.

The analysis revealed a moderate positive correlation between weekly preterm birth incidence and Temp_avg, $\mathrm{r}=0.306, \mathrm{n}=52, \mathrm{p}=0.027$ and a moderate positive correlation between weekly preterm birth incidence and Temp_var, $\mathrm{r}=0.307, \mathrm{n}=52, \mathrm{p}=0.007$.

If the ascending trend of the Temp_avg and Temp var is maintained, the linear regression model $(\mathrm{p}<0.027$, respectively $\mathrm{p}<0.007$ ) between $\mathrm{PB}$ and Temp_avg and Temp_var can explain 9.4 to $13.8 \%$ of the preterm births in one week with similar meteorological characteristic.

The number of preterm births in a week can be predicted with the regression equation of $\mathrm{PB}=$ $1,636+.091\left(\mathrm{Tem} \_\mathrm{Avg}\right)$ or $\mathrm{PB}=0.720+0.073$ (Tem_var) "Figure 1" and "Figure 2".

Table II. Monthly frequency of the preterm birth and the meteorological parameters in Cluj-Napoca 2014.

\begin{tabular}{|c|c|c|c|c|c|c|}
\hline \multirow[t]{2}{*}{ Month } & \multicolumn{2}{|c|}{ Preterm birth } & \multirow{2}{*}{$\begin{array}{l}\text { Average } \\
\text { Temperature }\left({ }^{\circ} \mathrm{C}\right)\end{array}$} & \multirow{2}{*}{$\begin{array}{l}\text { Sea Level } \\
\text { Pressure (hPa) }\end{array}$} & \multirow{2}{*}{$\begin{array}{l}\text { Wind } \\
(\mathrm{km} / \mathrm{h})\end{array}$} & \multirow{2}{*}{$\begin{array}{l}\text { Precipitation } \\
(\mathrm{mm})\end{array}$} \\
\hline & no & $\%$ & & & & \\
\hline January & 7 & 5.07 & 0 & 1016 & 6 & 0.9 \\
\hline February & 8 & 5.79 & 4 & 1017 & 6 & 0.5 \\
\hline March & 6 & 4.34 & 9 & 1016 & 7 & 0.2 \\
\hline April & 9 & 6.52 & 11 & 1013 & 8 & 0.5 \\
\hline May & 16 & 11.59 & 15 & 1013 & 8 & 1.4 \\
\hline June & 22 & 15.94 & 18 & 1015 & 8 & 2.6 \\
\hline July & 25 & 18.11 & 20 & 1013 & 7 & 2.1 \\
\hline August & 10 & 7.24 & 20 & 1014 & 6 & 0.7 \\
\hline September & 7 & 5.07 & 17 & 1017 & 7 & 0.8 \\
\hline October & 7 & 5.07 & 11 & 1020 & 6 & 1.2 \\
\hline November & 10 & 7.24 & 5 & 1020 & 6 & 1.2 \\
\hline December & 11 & 7.97 & 1 & 1019 & 6 & 1.2 \\
\hline
\end{tabular}

Table III. Pearson's product-moment correlation between weekly preterm birth frequency and main meteorological parameters.

\begin{tabular}{llllllllll}
\hline & Temp_avg & Temp_Var & Hum_Avg & Hum_Var & Pres_Avg & Pres_Var & Wind_vel & Precip \\
\hline r & 0.306 & 0.307 & -0.180 & 0.160 & -0.160 & -0.188 & 0.197 & 0.120 \\
\hline n & 52 & 52 & 52 & 52 & 52 & 52 & 52 & 52 \\
p & 0.027 & 0.007 & 0.202 & 0.258 & 0.257 & 0.183 & 0.162 & 0.396 \\
\hline
\end{tabular}




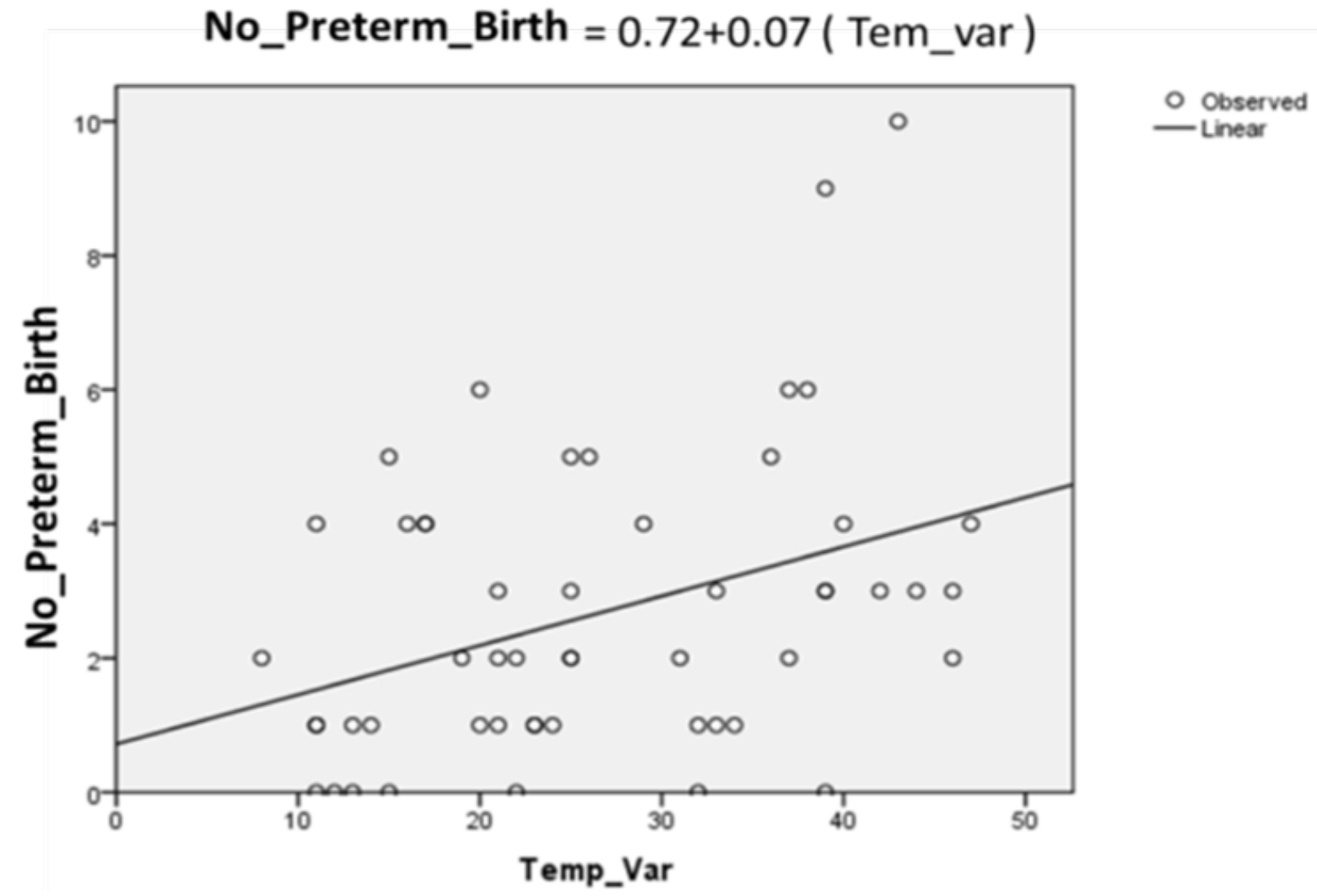

Figure 1. Linear regression between the number of preterm birth and the average temperature.

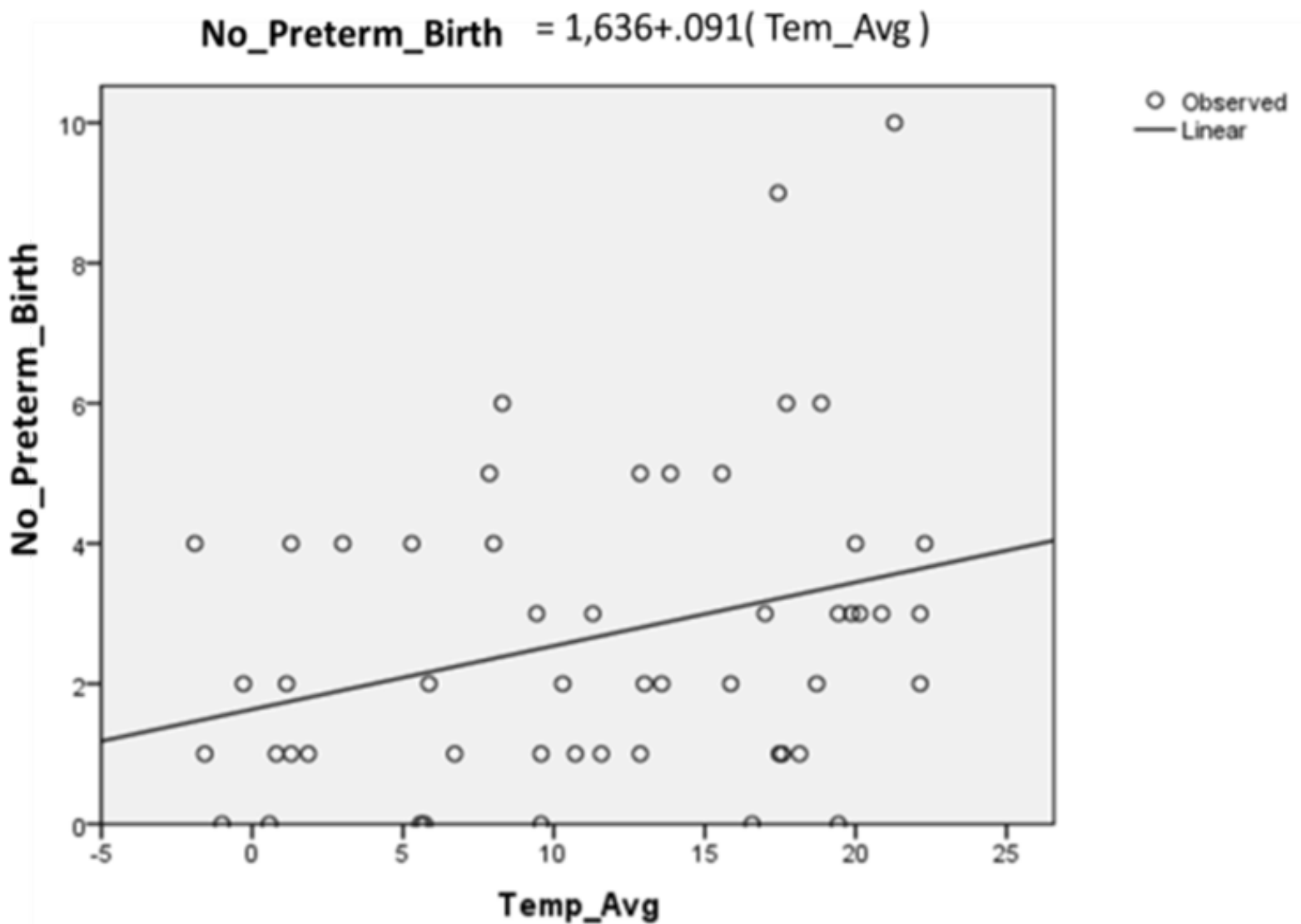

Figure 2. Linear regression between the number of preterm birth and temperature variation. 


\section{Discussion}

The effect of meteorological factors on preterm birth incidence is an important topic of global interest and has been previously approached in several recent studies [6]. Seasonal weather changes are known to have an important effect on the overall human morbidity especially for the infectious and cardiovascular diseases [17], but the influence that it may have on the pregnancy outcomes is still a topic of debate [18].

The present study, conducted in a region characterized by a temperate climate, has identified correlations between PB incidence and temperature variation, findings that can apply to others geographic regions with similar weather conditions.

High temperature variations during a week were found to be associated with an increased risk of preterm birth, in agreement with other published studies [8].

In the era of "big data" weather information can be integrated to explain some aspects of premature births incidence and in creating specific patterns to each geographic area.

Although larger studies will be needed to support the pattern, the research had a homogenous medical context, sustained by protocols of prevention and treatment of preterm birth used in our hospital during the period under review.

Using the existing methods of weather forecast, these patterns can be used to anticipate the risk of a growing number of premature births on the following week that may require a special management of the resources in the Obstetrics and Neonatology services, thus having clinical and financial benefits.

The information obtained reinforces the idea that meteorological factors variation should be considered when calculating the risk score for preterm birth, depending on the geographic region.

Specific variation in the behavior of the meteorological factors may constitute a partial explanation for the different incidence of PB in the world, together with the quality of care, social and economic factors and race [4].

Available evidence sustains the relationships between weather changes or seasonality and hypertensive disorders of pregnancy [19], pregnancy length and birth weight. The review highlights a higher incidence of the premature birth and lower birth weight during the months of summer and winter, or associated with heat wave [4].

In a large study conducted in Japan, the monthly average temperature influence on the rates of preterm births was determined to be inversely correlated $(\mathrm{R}=-0.424$, $\mathrm{p}=0.003)$ in the winter and positively correlated in the summer $(\mathrm{R}=0.549, \mathrm{p}<0.001)$ [10]. Another study conducted in Israel, determined that preterm birth rates increased as monthly average maximum temperature increased [19].
The influence of temperature during the four weeks preceding birth was examined in an Australian study of 101,870 births, which reported a positive association with preterm birth between 28 and 36 gestational weeks $[6,20]$.

Also, pregnancy length seems to be more influenced by meteorological changes that occurred during certain gestational weeks. For example, exposure to extreme high temperature between 20 and 34 weeks of gestation were associated with a higher risk of premature birth then an exposure during 35-36 weeks of gestation [21].

Studies from Europe that focused on the relationship between preterm birth and temperature in the last week preceding delivery, were conducted in Germany [22] and England [8], and reported no correlation of the two parameters.

Short-term association between PB and temperature variation, also approached in the present study, was considered to provide valid evidence, since this type of association cannot be explained by socioeconomically differentiated patterns [23].

Seasonal patterns in birth outcomes revealed in studies conducted in developing countries are due more to changes in nutrition habits, different infectious diseases, seasonal work or air pollution $[24,25]$.

Also, chronic stress due to a relatively constrain of the outdoor activities in the hot summer weather of June and August was associated with very low birth weight [26].

The biological mechanisms that could elucidate the influence of temperature on preterm birth are unclear. One possible hypothesis argues that dehydration caused by heat exposure, could decrease uterine blood flow and increase pituitary secretion of antidiuretic hormone and oxytocin that can induce labor [27].

Also, high temperature may increase blood viscosity and cholesterol levels, other known risk factors for preterm birth [27].

Furthermore, animal studies demonstrated that heat exposure may increase the secretion of proinflammatory cytokines and oxytocin to induce labor [28].

Heat stress also leads to the release of heat-shock pro $\rightarrow$ teins (HSPs), including HSP-70, in humans, and increased levels of HSP-70 has been linked to preterm birth [28].

On the other hand, extreme cold was shown to produce vasoconstriction and increase blood viscosity thus affecting pregnancy length $[29,30]$.

Some shortcomings of our study may be the retrospective aspect, the short period of the study of one year and personal history of premature birth or local infections of the patients. Also, we took into consideration the date of birth not the date of conception, therefore the births included at the start and the end of the study were not taken in consideration. The solution to lower the magnitude of this bias would be future studies using larger cohorts for 
longer periods of time [7].

In conclusion, our study strengthens the idea of a correlation between temperature changes and several birth complications.

Even in moderate climate areas, obstetricians should be aware of the influence that unstable weather may have on the pregnancy outcomes, especially in the spring and summer months. Due to the climate change, new research to estimate the effects of environmental exposures that can increase the risk of preterm birth can be of great future public health.

\section{References}

1. Koullali B, Oudijk MA, Nijman TA, Mol BW, Pajkrt E. Risk assessment and management to prevent preterm birth. Semin Fetal Neonatal Med. 2016;21(2):80-88.

2. Muglia LJ, Katz M. The enigma of spontaneous preterm birth. N Engl J Med. 2010;362(6):529-535.

3. Blencowe H, Cousens S, Oestergaard MZ, Chou D, Moller AB, Narwal R, et al. National, regional, and worldwide estimates of preterm birth rates in the year 2010 with time trends since 1990 for selected countries: a systematic analysis and implications. Lancet. 2012;379(9832):2162-2172.

4. Beltran AJ, Wu J, Laurent O. Associations of meteorology with adverse pregnancy outcomes: a systematic review of preeclampsia, preterm birth and birth weight. Int J Environ Res Public Health. 2013;11(1):91-172.

5. Woodward A, Smith KR, Campbell-Lendrum D, Chadee DD, Honda Y, Liu Q, et al. Climate change and health: on the latest IPCC report. Lancet. 2014;383(9924):1185-1189.

6. Vicedo-Cabrera AM, Olsson D, Forsberg B. Exposure to seasonal temperatures during the last month of gestation and the risk of preterm birth in Stockholm. Int J Environ Res Public Health. 2015;12(4):3962-3978.

7. Strand LB, Barnett AG, Tong S. Methodological challenges when estimating the effects of season and seasonal exposures on birth outcomes. BMC Med Res Methodol. 2011 Apr 18;11:49.

8. Lee SJ, Steer PJ, Filippi V. Seasonal patterns and preterm birth: a systematic review of the literature and an analysis in a Londonbased cohort. BJOG. 2006;113(11):1280-1288.

9. Flouris AD, Spiropoulos Y, Sakellariou GJ, Koutedakis Y. Effect of seasonal programming on fetal development and longevity: links with environmental temperature. Am J Hum Biol. 2009;21(2): p. 214-216.

10. Matsuda S, Kahyo H. Seasonality of preterm births in Japan. Int J Epidemiol. 1992;21(1):91-100.

11. Pop G. Depresiunea Transilvaniei [The Transylvanian Depression]. Cluj-Napoca: Ed. Presa Universitară Clujeană; 2001. 12. Dezsi S. Ţara Lăpuşului. Studiu de geografie regională [Lapus county. A study of regional geography]. Cluj-Napoca: Ed. Presa Universitară Clujeană; 2006.

13. Mac I, Sorocovschi V. Intercondiţionări morfoclimatice în Depresiunea Transilvaniei cu efecte semnificative în peisaj
[Morphoclimatic interconditioning in Transylvania with significant landscape changes]. B.S.S.G. 1982; VI(LXXXVI). 14. Irimuş A. Relieful pe domuri şi cute diapire în Depresiunea Transilvaniei [The relief on domes and diapir folds in the Transylvanian Depression]. Cluj-Napoca: Ed. Presa Universitară Clujeană; 1998.

15. Mac I. Mac, I. Types of landslide in the Transylvanian Depression with differentiated effect on the morphology of the slope. SUBB - GG. 1997; XLII: p. 1-2.

16. The Weather Company L. wunderground.com. Available from: https://www.wunderground.com

17. Huang J, Wang J, Yu W. The lag effects and vulnerabilities of temperature effects on cardiovascular disease mortality in a subtropical climate zone in China. Int J Environ Res Public Health. 2014;11(4):3982-3994.

18. Ha S, Liu D, Zhu Y, Kim SS, Sherman S, Mendola P. Ambient Temperature and Early Delivery of Singleton Pregnancies. Environ Health Perspect. 2017;125(3):453-459.

19. Steegers EA, von Dadelszen P, Duvekot JJ, Pijnenborg R. Preeclampsia. Lancet. 2010;376(9741):631-644.

20. Yackerson N, Piura B, Sheiner E. The influence of meteorological factors on the emergence of preterm delivery and preterm premature rupture of membrane. J Perinatol. 2008;28(10):707-711.

21. Wang J, Williams G, Guo Y, Pan X, Tong S. Maternal exposure to heatwave and preterm birth in Brisbane, Australia. BJOG. 2013;120(13):1631-1641.

22. He JR, Liu Y, Xia XY, Ma WJ, Lin HL, Kan HD, et al. Ambient Temperature and the Risk of Preterm Birth in Guangzhou, China (2001-2011). Environ Health Perspect. 2016;124(7):1100-1106.

23. Wolf J, Armstrong B. The association of season and temperature with adverse pregnancy outcome in two German states, a time-series analysis. PLoS One. 2012;7(7):e40228.

24. Darrow LA, Strickland MJ, Klein M, Waller LA, Flanders WD, Correa A, et al. Seasonality of birth and implications for temporal studies of preterm birth. Epidemiology. 2009;20(5):699706.

25. Rayco-Solon P, Fulford AJ, Prentice AM. Differential effects of seasonality on preterm birth and intrauterine growth restriction in rural Africans. Am J Clin Nutr. 2005;81(1):134-139.

26. Schifano P, Lallo A, Asta F, De Sario M, Davoli M, Michelozzi P. Effect of ambient temperature and air pollutants on the risk of preterm birth, Rome 2001-2010. Environ Int. 2013;61:77-87.

27. Hartig T, Catalano R. Cold summer weather, constrained restoration, and very low birth weight in Sweden. Health Place. 2013;22:68-74.

28. Basu R, Malig B, Ostro B. High ambient temperature and the risk of preterm delivery. Am J Epidemiol. 2010;172(10):11081117.

29. Dadvand P, Basagaña X, Sartini C, Figueras F, Vrijheid M, de Nazelle A, et al. Climate extremes and the length of gestation. Environ Health Perspect. 2011;119(10):1449-1453.

30. Bruckner TA, Modin B, Vågerö D. Cold ambient temperature in utero and birth outcomes in Uppsala, Sweden, 1915-1929. Ann Epidemiol. 2014;24(2):116-121. 